\title{
Secreted Phosphoprotein 24 kD Inhibits Growth of Human Prostate Cancer Cells Stimulated by BMP-2
}

\author{
LIFENG LAO ${ }^{1}$, JIA SHEN ${ }^{2}$, HAIJUN TIAN ${ }^{2}$, QINGQIANG YAO ${ }^{2}$, YAWEI LI ${ }^{2}$, \\ LIE QIAN $^{1}$, SAMUEL S. MURRAY ${ }^{3-5}$ and JEFFREY C. WANG ${ }^{6}$ \\ ${ }^{1}$ Department of Orthopaedic Surgery, Renji Hospital, School of Medicine, \\ Shanghai Jiao Tong University, Shanghai, P.R. China; \\ ${ }^{2}$ Department of Orthopaedic Surgery, University of California at Los Angeles (UCLA), Los Angeles, CA, U.S.A.; \\ ${ }^{3}$ Geriatric Research, Education, and Clinical Center, \\ VA Greater Los Angeles Health Care System, Sepulveda, CA, U.S.A.; \\ ${ }^{4}$ Department of Medicine, University of California, Los Angeles, CA, U.S.A.; \\ ${ }^{5}$ Biomedical Engineering Interdepartmental Program, \\ University of California, Los Angeles, CA, U.S.A.; \\ ${ }^{6}$ Department of Orthopaedic Surgery, Keck School of Medicine, \\ University of Southern California, Los Angeles, CA, U.S.A.
}

\begin{abstract}
Background/Aim: Secreted phosphoprotein $24 \mathrm{kD}$ (spp24) has been shown to inhibit bone morphogenetic protein 2 (BMP2)-induced cancer growth in several tumor models. In this study, we aimed to investigate the effects spp 24 on the growth of prostate cancer caused by BMP2 in vitro and in vivo. Materials and Methods: The effects of BMP2 and spp24 on PC-3 cell viability were analyzed using MTT (3-(4,5dimethylthiazol-2-yl)-2,5-diphenyl tetrazolium bromide) assay. A subcutaneous tumor model and intratibial tumor model was established using PC-3 cells. Tumor growth was assessed through gross examination and radiography during the experiment. Then, after sacrifice, tumor cell apoptosis and tumor cell proliferation were assessed by terminal deoxynucleotidyl transferase dUTP nick-end labeling (TUNEL) assay and immunochemical analysis. Results: BMP2 stimulated the PC-3 cell proliferation in vitro and spp24 could abolish the effect of BMP2. In a xeneograft tumor model, BMP2 promoted the subcutaneous and intratibial tumor growth, while spp 24 dramatically inhibited the tumor growth induced by BMP2. Histological examination showed that spp24 also abolished the
\end{abstract}

This article is freely accessible online.

Correspondence to: Dr. Lie Qian, MD, Department of Orthopaedic Surgery, Renji Hospital, School of Medicine, Shanghai Jiao Tong University, 160 Pujian Road, Shanghai 200127, China. Tel: +86 2158394262, Fax: +86 2158394262, e-mail: lqianrj@sina.com

Key Words: Prostate cancer, bone morphogenetic protein 2, secreted phosphoprotein $24 \mathrm{kD}$, bone metastasis.
BMP2-induced proliferating cell nuclear antigen (PCNA) expression and promoted tumor cell apoptosis. Conclusion: Spp24 can inhibit the growth of prostate cancer and its bone metastasis induced by BMP2; spp24 may have great potential to be a therapeutic agent in clinical situations.

Prostate cancer is one of the most common cancers in elderly men (1). Prostate cancer may account for $10 \%$ of all male cancer-related deaths (2). Prostate cancer-caused death may due to its invasion and metastasis (3). It has been shown that most patients can survive longer than 10 years if metastasis does not occur (4). Surgery, radiation therapy, endocrinological treatment and chemotherapy have been used in the treatment of prostate cancer alone or in combination. However, current therapies are not often curative and relapse often happened. Novel therapeutic strategies are needed for the treatment of prostate cancer. Some studies have shown that active components of natural products $(5,6)$, antagonists of hypothalamic growth hormone-releasing hormone (7), monoclonal antibodies $(8,9)$ and microRNA $(10,11)$ could suppress prostate cancer in vitro or in vivo.

Bone morphogenetic proteins (BMPs) can induce the formation of bone and cartilage. They are also involved in pivotal morphogenetic signals (12). Cancerous disease is often related with misregulation of the BMP signaling system. Recombinant human BMPs (rhBMPs) have been used in orthopedic applications. RhBMP2 causes more overgrown bone than any other BMPs and has been well accepted as an osteoinductive growth factor. BMPs and /or BMP receptor are also expressed in several malignancies (13). It has been shown that BMPs could promote tumor 
growth, invasion and metastasis (14-16). Dai et al. (17) have shown that BMP6 promotes osteoblastic prostate cancer bone metastases. Few studies have indicated the role of rhBMP2 on prostate cancer $(18,19)$.

Secreted phosphoprotein $24 \mathrm{kD}$ (spp24) is a bone matrix protein that can bind to and affect the activity of BMPs (20, 21). Spp24 exists in the bone environment in several forms and can inhibit the BMP-induced bone formation. Several studies have shown that spp24 could suppress pancreatic cancer growth (22) and lung cancer (23) caused by BMP2. Previous studies have shown that BMP2 could promote proliferation and migration of PC3 cells $(19,24)$. However, it is not clear on the effects of spp24 on prostate cancer induced by BMP2. In this study, we investigated the influence of BMP2 on prostate cancer in vitro and in vivo. Furthermore, we also showed the ability of spp24 on the effects induced by BMP2.

\section{Materials and Methods}

Cell culture and experimental materials. The human prostate cancer cell line PC-3 was obtained from America Type Cell Collection (ATCC; Manassas, VA, USA). PC-3 cells were maintained in F-12K medium with $10 \%$ FBS and antibiotics (Fisher Scientific, Pittsburgh, PA, USA) in a humidified atmosphere of $95 \%$ air and $5 \% \quad \mathrm{CO}_{2}$ at $37^{\circ} \mathrm{C}$ with medium change every three days. Recombinant human BMP2 was purchased from MEDTRONIC, INC. (Medtronic Sofamor Danek, Minneapolis, MN, USA). Recombinant spp24 was produced in a bacterial expression vector as described previously (25).

Cell viability assay. PC-3 cells $\left(4 \times 10^{3}\right.$ cells/well) were plated in $96-$ well plates in F-12K medium containing $10 \%$ FBS and incubated for $24 \mathrm{~h}$. Then, the cells were cultured with serum-free medium containing different concentrations of RhBMP2 and Spp24 (50 $\mathrm{ng} / \mathrm{ml} \mathrm{BMP2} \mathrm{and} 50 \mathrm{ng} / \mathrm{ml} \mathrm{BMP} 2+100 \mu \mathrm{g} / \mathrm{ml} \mathrm{Spp} 24$ ) for 24,48 and $72 \mathrm{~h}$, respectively. Then, the medium was removed and another medium (without FBS) containing 10\% 3-(4, 5-dimethylthiazolyl2)-2,5-diphenyltetrazolium bromide (MTT) solution $(0.5 \mathrm{mg} / \mathrm{ml}$ in PBS, Sigma, MO, USA) was added into each well. After a 4-h incubation at $37^{\circ} \mathrm{C}$, the fomazan crystals formed were dissolved in $100 \mu$ of dimethyl sulfoxide (Sigma, St. Louis, MO, USA). The absorbance at $570 \mathrm{~nm}$ was read using a Biotek microplate reader (BioTek Instruments Inc, Winooski, VT, USA). The data were displayed as the mean \pm SD of six wells for each group.

In vivo experimental groups. All mice underwent implantation of cells in both a subcutaneous model and an intratibial injection. Then, they were randomly divided into three groups. A control group received $\mathrm{PC}-3$ cells alone; BMP-2 group received PC-3 cells+RhBMP2 $(10 \mu \mathrm{g})$; spp24 group received PC-3 cells+RhBMP2 $(10 \mu \mathrm{g})+\mathrm{spp} 24(1.0 \mathrm{mg})$. There were six animals in each group. Repeat injections of $2 \mu \mathrm{g}$ RhBMP and spp24 (1.0 mg) were given weekly until the end of the study period.

Subcutaneous tumor model and intratibial tumor model. The subcutaneous tumor xenograft model was established as previously reported (23). Eighteen 8-week-old male nude mice (BALB/c nu/nu) weighted 20-25 g were housed under specific pathogen-free facilities. All mice were acclimated for one week and, then, received subcutaneous injections of $5 \times 10^{5}$ PC- 3 cells on their back. Briefly, PC- 3 cells were suspended in $30 \mu \mathrm{l}$ of PBS. After the mice were anesthetized with ketamine $(4.0 \mathrm{mg} / 100 \mathrm{~g})$, the skin on back was prepped with $70 \%$ ethanol and betadine. The PC-3 cells were then injected into the subcutaneous space on the back of mice. All the experiments were carried out according to the guidelines of animal welfare committee. The protocol adopted here was approved by the Animal Use Committee of Renji Hospital.

In addition, the intratibial tumor model was also established as previously reported (23). Briefly, after anesthetization, the skin was prepped with $70 \%$ ethanol and betadine. Then, a total of $1 \times 10^{6}$ cancer cells in $30 \mu \mathrm{l}$ of PBS were injected into the proximal tibial cavity through the proximal tibial plateau with a 27.5 -gauge needle. The wound was closed with VICRYL ${ }^{\circledR}$ suture.

Measurement of tumor size and weight. Tumor size and weight were measured as previously described (23). The tumor sizes were measured weekly using digital calipers and calculated by the average of the greatest length and width. All mice were sacrificed at 10 weeks. The tumor specimens were dissected and tumor weights determined using a precision electronic balance.

Radiographic analysis. Prior to their sacrifice, animals were anesthetized as described above. Radiographs were obtained using a Radiography System (Faxitron, IL, USA) exposed to X-ray at $35 \mathrm{kVp}$ for $6 \mathrm{~s}$. The bone lesions were evaluated blindly by two observers. The bone lesions were scored as following: 0 , normal; 1 , lystic lesions present within the medullary canal only; 2, involving one cortex; 3 , involving two cortexes. The X-ray images were evaluated by three independent observers who were blinded with the study groups.

In vivo terminal deoxynucleotidyl transferase dUTP nick-end labeling (TUNEL) apoptosis assay and immunohistochemistry. The tumor specimens were cut into pieces and fixed in $4 \%$ paraformaldehyde at $4^{\circ} \mathrm{C}$ for $72 \mathrm{~h}$, dehydrated through a series of ascending ethanol solution (40\%-100\%), embedded in paraffin and sliced for TUNEL apoptosis assay and immunohistochemistry.

TUNEL apoptosis assay. Sections were firstly dewaxed with dimethylbenzene and rehydrated with ethanol solution (100\%-70\%) and distilled water. Then, the sections were incubated with $20 \mu \mathrm{g} / \mathrm{ml}$ proteinase $\mathrm{K}$ (without DNase) for $20 \mathrm{~min}$ at $37^{\circ} \mathrm{C}$. After washing for three times, the sections were incubated with $3 \% \mathrm{H}_{2} \mathrm{O}_{2}$ solution for $20 \mathrm{~min}$ at room temperature. After washing with PBS for three times, they were incubated with the TUNEL apoptosis assay solution for $60 \mathrm{~min}$ at $37^{\circ} \mathrm{C}$. The reaction was stopped using the solution supplied by the TUNEL apoptosis assay kit. Then, the sections were incubated with horseradish peroxidase (HRP)conjugated streptavidin solution for $30 \mathrm{~min}$ at room temperature. Finally, sections were developed with DAB kit and hematoxylin stanining. Four randomly selected fields from each section were analyzed. The percent of TUNEL-positive apoptotic cells were calculated in each mouse.

Immunohistochemistry. Tumor sections were firstly dewaxed and rehydrated. Then, the sections were heated with pressure in retrieval 
solution for $30 \mathrm{~min}$. After incubated with 5\% BSA to block nonspecific staining, sections were incubated with proliferating cell nuclear antigen (PCNA) monoclonal antibodies diluted as instructed overnight at $4^{\circ} \mathrm{C}$. Then, the sections were incubated in HRPconjugated secondary antibody at $37^{\circ} \mathrm{C}$ for $1 \mathrm{~h}$. Finally, sections were developed with DAB kit. The images were acquired using an Olympus Microscope (CX40, Olympus, Japan) with a digital camera (ProgRes C14; Jenoptic, Jena, Germany). PCNA-positive cells were numbered using software (Digital Micro System, Jena, Germany). Four randomly selected fields from each section were analyzed. The percent of PCNA-positive cells were calculated in each mouse.

Statistical analysis. Data management and statistical analysis were performed by SPSS16.0 (SPSS Inc, Chicago, IL, USA). Data were expressed as mean \pm standard deviation and analyzed by MannWhitney $U$-test. Statistical significance was defined as $p \leq 0.05$.

\section{Results}

Spp24 inhibited PC-3 cell proliferation stimulated by BMP2. Figure 1 shows the PC-3 cell proliferation. The PC-3 cell proliferation was increased with time in all groups. PC-3 cells treated with BMP2 showed an increase in proliferation files compared with the control, especially at $72 \mathrm{~h}(p<0.05)$. However, spp24 changed PC-3 cell ability stimulated by $\mathrm{BMP} 2$, in particular at 48 and $72 \mathrm{~h}(p<0.05)$.

Spp24 inhibited the subcutaneous tumor growth promoted by $B M P 2$. We further observed the effects of BMP2 and spp24 on tumor growth in vivo using a subcutaneous tumor model (Figure 2). The tumor sizes were increased over time (Figure $2 \mathrm{~A}$ and $2 \mathrm{~B}$ ). BMP-2 significantly promoted tumor growth during the observation period. BMP-2 had increased the tumor size by 2.0 -fold (Figure $2 \mathrm{~B}$ ) and the tumor weight by 3.0-fold (Figure 2C) compared with the control. The spp24 significantly blocked the effects of BMP2 on tumor growth. In some mice treated with spp24, the size of the tumor mass became almost undetectable (Figure 2A).

Spp24 inhibited the intratibial tumor growth promoted by $B M P 2$. We also observed the effects of BMP2 and spp24 on tumor growth in vivo using an intratibial tumor model (Figure 3). Excellent agreement was found between observers (Kappa value $=0.86$ ). The bone destructions were heavier in mice treated with BMP2 than the control (Figure $3 \mathrm{~A})$. The radiological score was significantly higher in BMP2-treated mice compared with the control (Figure 3B). However, spp24 significantly inhibited the bone destructions stimulated by BMP2. The radiological score was obviously decreased in treated mice with both BMP2 and spp24 compared with the mice in control and the mice treated with BMP2 alone (Figure 3B).

TUNEL- and PCNA-positive cell in tumor specimens. Cell apoptosis in tumor specimens were assayed using TUNEL

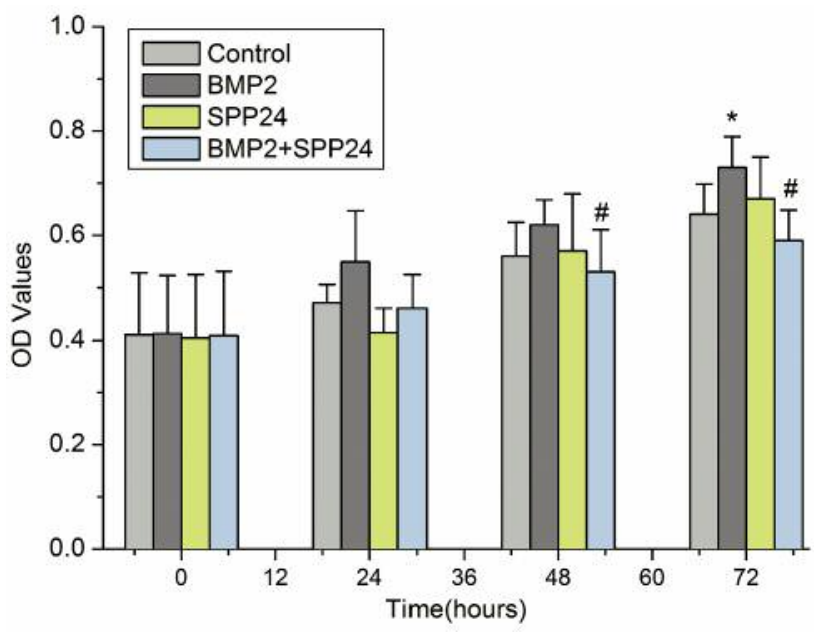

Figure 1. The effects of spp24 on the proliferation of PC-3 cells stimulated by bone morphogenetic protein-2 (BMP2). BMP2 significantly stimulates $P C-3$ cell proliferation at 72 h. However, spp 24 could abolish the effects of BMP2 at 48 and $72 h . * p<0.05 \mathrm{vs}$. control; ${ }^{\#} p<0.05$ vs. BMP2 group.

staining (Figure 4). Few TUNEL-positive cells were observed in control and BMP2 groups $(<5.0 \%)$. However, obvious TUNEL-positive cells were found in tumors of mice treated with both BMP2 and spp24. Spp24 probably inhibited tumor growth by inducing tumor cell apoptosis.

We also investigated the tumor cell proliferation activity in vivo by immunohistochemical staining for PCNA (Figure 5). BMP2 groups showed stronger PCNA-positive cells compared with the control and BMP+spp24 group. Consistent with the in vitro data, spp24 also inhibited the in vivo cell proliferation stimulated by BMP2.

\section{Discussion}

Several therapeutic strategies, such as surgery, radiation therapy, endocrinological treatment, have been used for prostate cancer management. However, current therapies are not often curative and relapses often happen. Some studies have indicated that tumor originating from prostate can express BMPs $(19,26,27)$ and BMPs may stimulate tumor cell proliferation, invasion and metastasis in vitro and in vivo (27). In this study, we showed that BMP2 could stimulate prostate cancer cell proliferation in vitro and tumor growth and bone metastasis in vivo. We further demonstrated that a bone matrix protein, spp24, could abolish the effects of BMP2 on prostate cancer. Our data showed that spp24 have great potential to be a therapeutic agent.

BMPs are a group of growth factors. BMP2 through BMP7 belong to the transforming growth factor-beta (TGF$\beta$ ) superfamily of proteins. Misregulation of BMP signal 

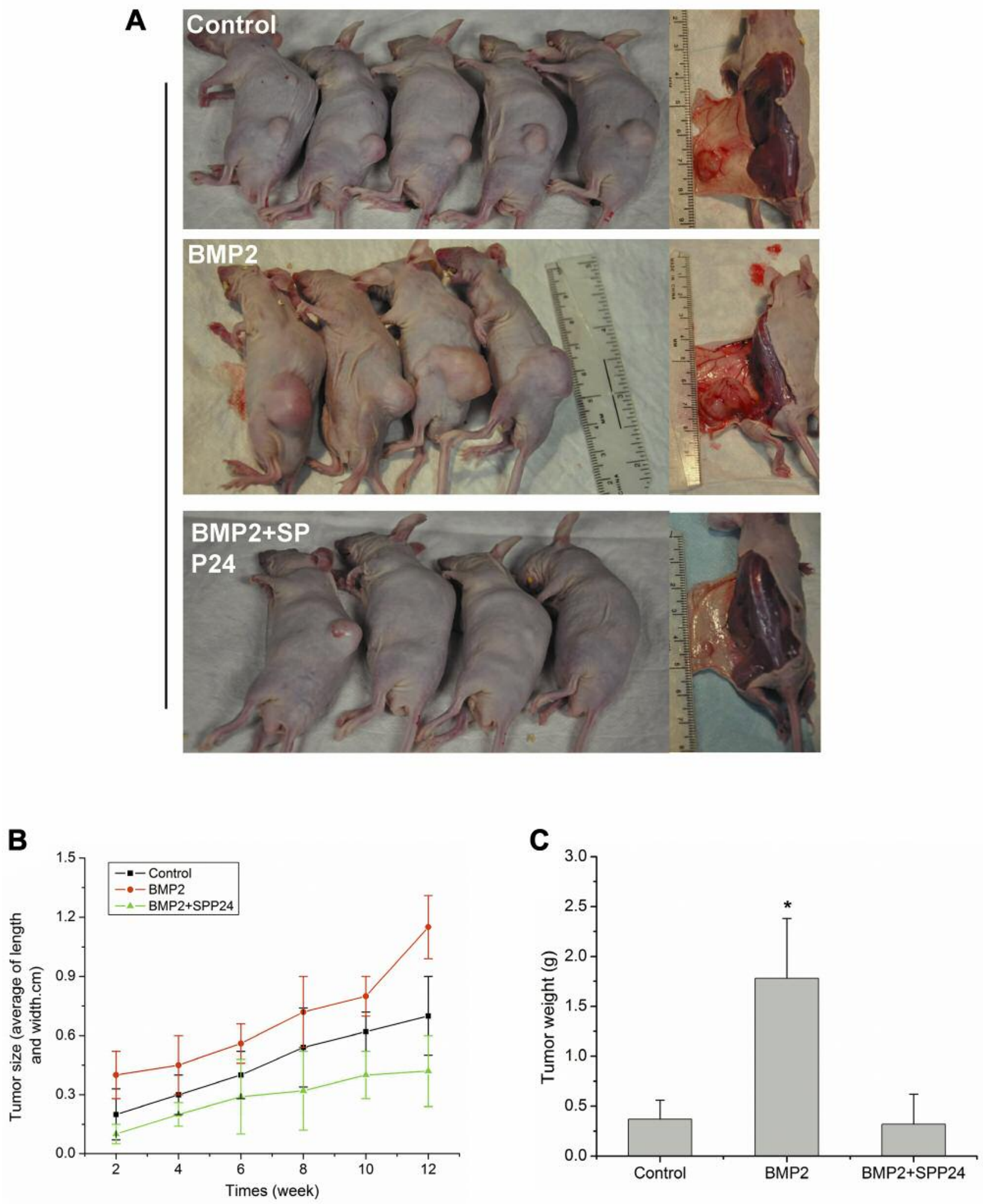

Figure 2. Subcutaneous tumor formation and growth in control, bone morphogenetic protein 2 (BMP2) and BMP2+ secreted phosphoprotein 24 $k D$ (SPP24) groups at 12th week. A: The gross observation at necropsy; B: The tumor growth curves; $C$ : The tumor weight at the 12 weeks, $p<0.01$ vs. other groups. 
A
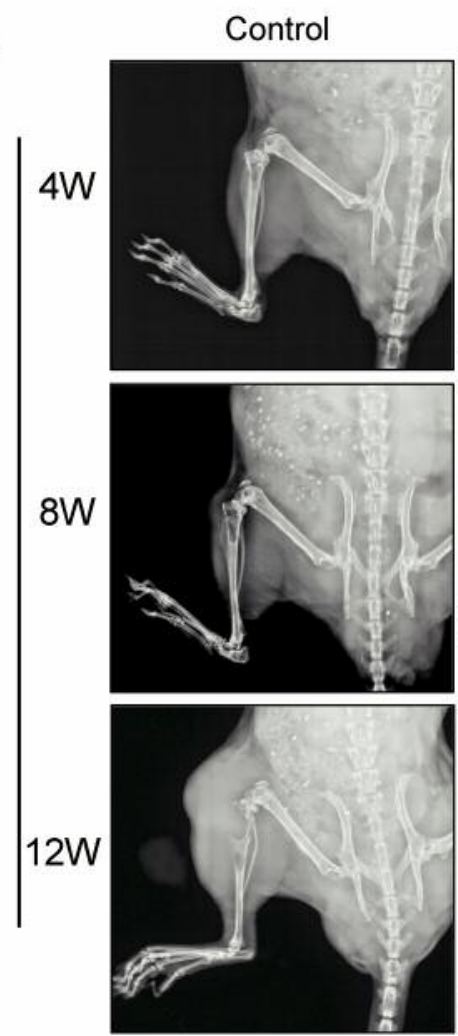
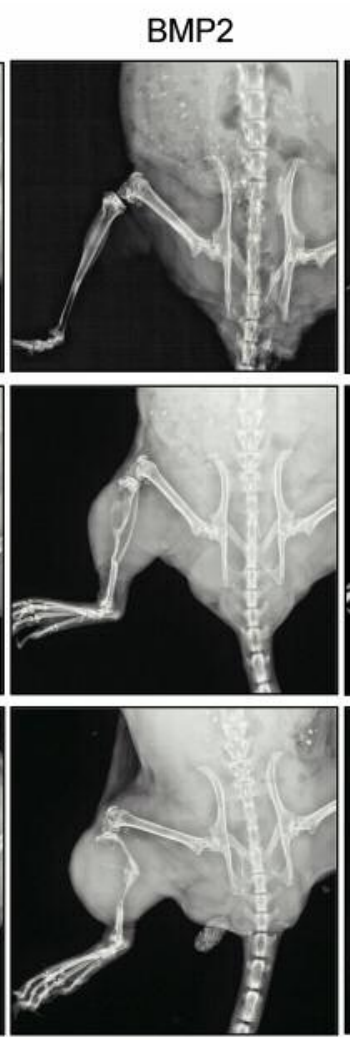

BMP2+SPP24
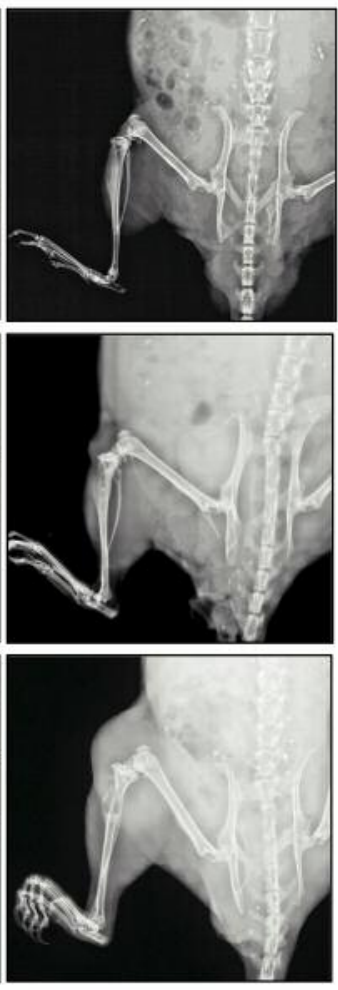

B

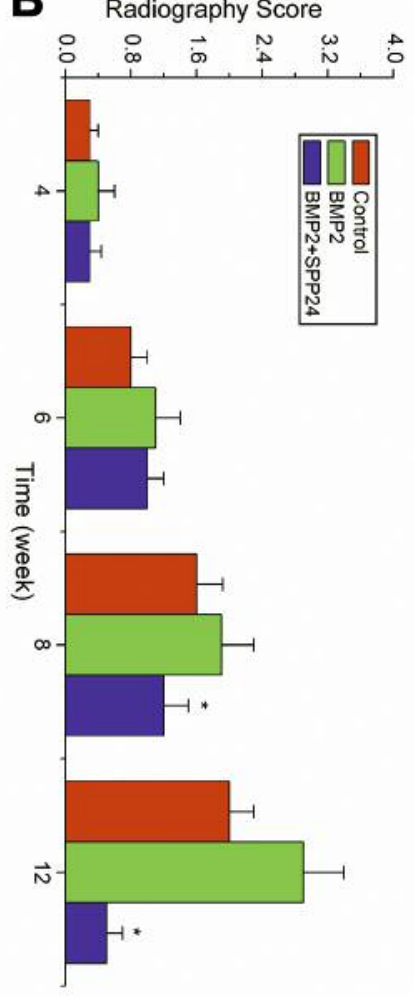

Figure 3. Intratibial tumor growth and radiographic analysis. A: The bone lesions at 4, 8 and 12 weeks in control and experimental groups. B: The radiographic score at 4, 6, 8 and 12 weeks, * ${ }^{*}<0.01$ vs. bone morphogenetic protein 2 (BMP2) group. SPP24, Secreted phosphoprotein $24 ; W$, week.

system may be related with the cancerous disease. Several studies have shown that BMPs could promote tumor invasion and metastasis (15-17). However, few studies have observed the effects of BMPs, especially BMP2, on prostate cancer. It has been shown that PC-3 cells expresse the BMP receptor (19). We hypothesized that BMP may influence the activity of PC-3 cells. Few previous studies have demonstrated that BMP2 stimulates the proliferation, migration and invasion of PC3 cells $(19,24)$. In the present study, we observed that BMP2 could stimulate PC-3 cell proliferation in vitro. In subcutaneous and intratibial tumor model, our data also showed that BMP2 markedly promoted the subcutaneous and intratibial tumor growth. PCNA-1, a proliferation biomarker, positive cells were commonly found in tumor specimens of BMP2-treated mice, which also indicated that BMP2 dramatically stimulated cell proliferation. Our data further confirmed previous findings that BMP could stimulate cancer cell growth in vitro and in vivo.

It has been shown that inhibition of BMP/TGF- $\beta$ activity may limit tumor growth (23). Spp24 can bind with BMP2 and inhibit its osteogenic activity $(28,29)$. Several studies have indicated that spp24 could inhibit cancer cell proliferation and tumor growth $(22,23)$. Lee et al. showed that spp24 could ameliorate the effects of BMP2 on lung cancer in a subcutaneous and intratibial tumor model (23). Recently, Li et al. indicated that spp24 could block the stimulatory effects of BMP2 on pancreatic cancer in vitro and in a xenograft tumor model (22). However, it is not clear whether spp24 could influence the effects of BMP2 on prostate cancer. Our data showed that spp24 could ameliorate the effects of BMP2 on prostate cancer in vitro and in vivo. Our results also support the fact that spp24 may have great potential for the treatment of cancerous diseases.

Bone metastasis is the common complication of prostate cancer. Usually, bisphosphonate agents and radionuclide treatment are adopted in metastasized bone lesions. Lai et al. reported that osteoblast-derived BMP2 may enhance the migration of prostate cancer cell through Akt/ERK pathway $(19,30)$. Feeley et al. (19) also showed that BMPs influence the formation of the osteolytic prostate cancer lesions and noggin, a BMP antagonist, could inhibit the BMP-induced growth of osteolytic prostate cancer metastasis. Therefore, a BMP2 inhibitor may be used to block bone metastasis of prostate cancer. Lee et al. demonstrated that spp 24 could 

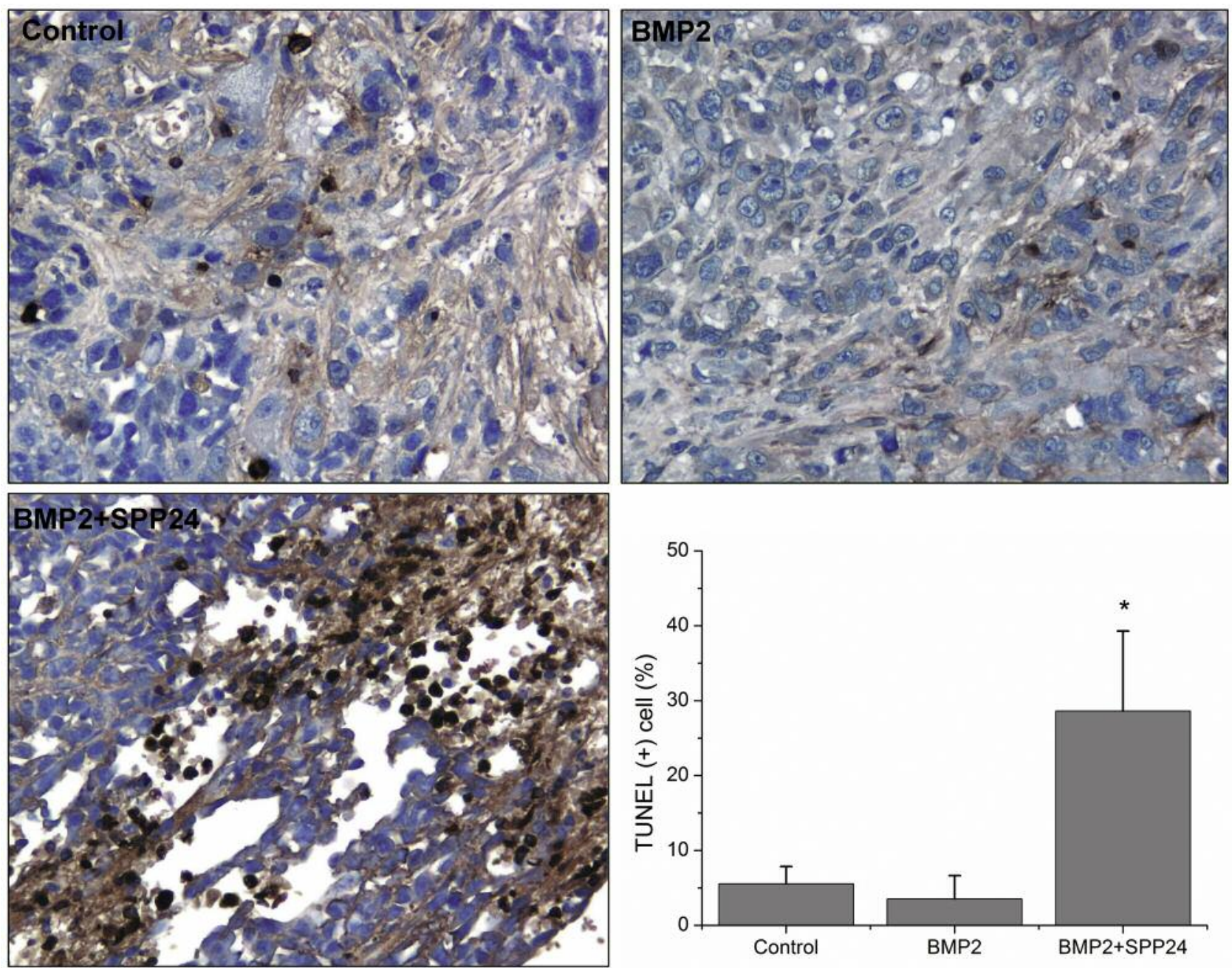

Figure 4. Cell apoptosis assay in vivo specimens using terminal deoxynucleotidyl transferase dUTP nick-end labeling (TUNEL) method ( $\times 200)$. No differences for cell apoptosis were found between the control and BMP2 group. More TUNEL-positive cells were found bone morphogenetic protein$2(B M P 2)+$ secreted phosphoprotein $24 k D(S P P 24)$ group compared to the control and BMP2 group. *p<0.01 vs. control and BMP2 group.

inhibit the bone destruction caused by lung cancer cells, thus indicating that spp24 may be used for treatment of bone metastasis (23). In our study, we also observed that spp24 could inhibit the bone destruction induced by BMP2.

The mechanism of spp24 on BMP2-induced cell proliferation is not completely understood. Spp24 may bind with BMP2 and, consequently, inhibit the function of BMP2. In addition, some studies have shown that spp24 could induce cancer cell apoptosis in vitro and in vivo (22). In our study, we also found that spp24 dramatically induced apoptosis of tumor cells; however, BMP2 did not affect cell apoptosis.

There are several limitations of this study. The mechanism of spp24 on BMP-induced effects is not investigated. Further exploration is needed. In addition, the bone metastasis model is established by intratibial injection of tumor cells, which is different with the pathophysiological conditions. Moreover, we did not show the effects of spp24 alone on prostate cancer growth, in this study.

In conclusion, our data showed that BMP2 can stimulate prostate cancer cell proliferation, tumor growth and bone metastasis. Spp24 obviously ameliorates the effects of BMP2 on prostate cancer. Spp24 may have a great potential for the treatment of prostate cancer and its bone metastasis.

\section{Acknowledgements}

This research was funded by Shanghai Pujiang Program (NO. 15PJD026), Medical-Engineering Joint Fund of Shanghai Jiao Tong University (NO. YG2014MS51), Shanghai Fund for Young Physician Development (NO. 20141051), Incubating Program for Clinical Research and Innovation of Renji Hospital (NO. PYXJS16-006). 

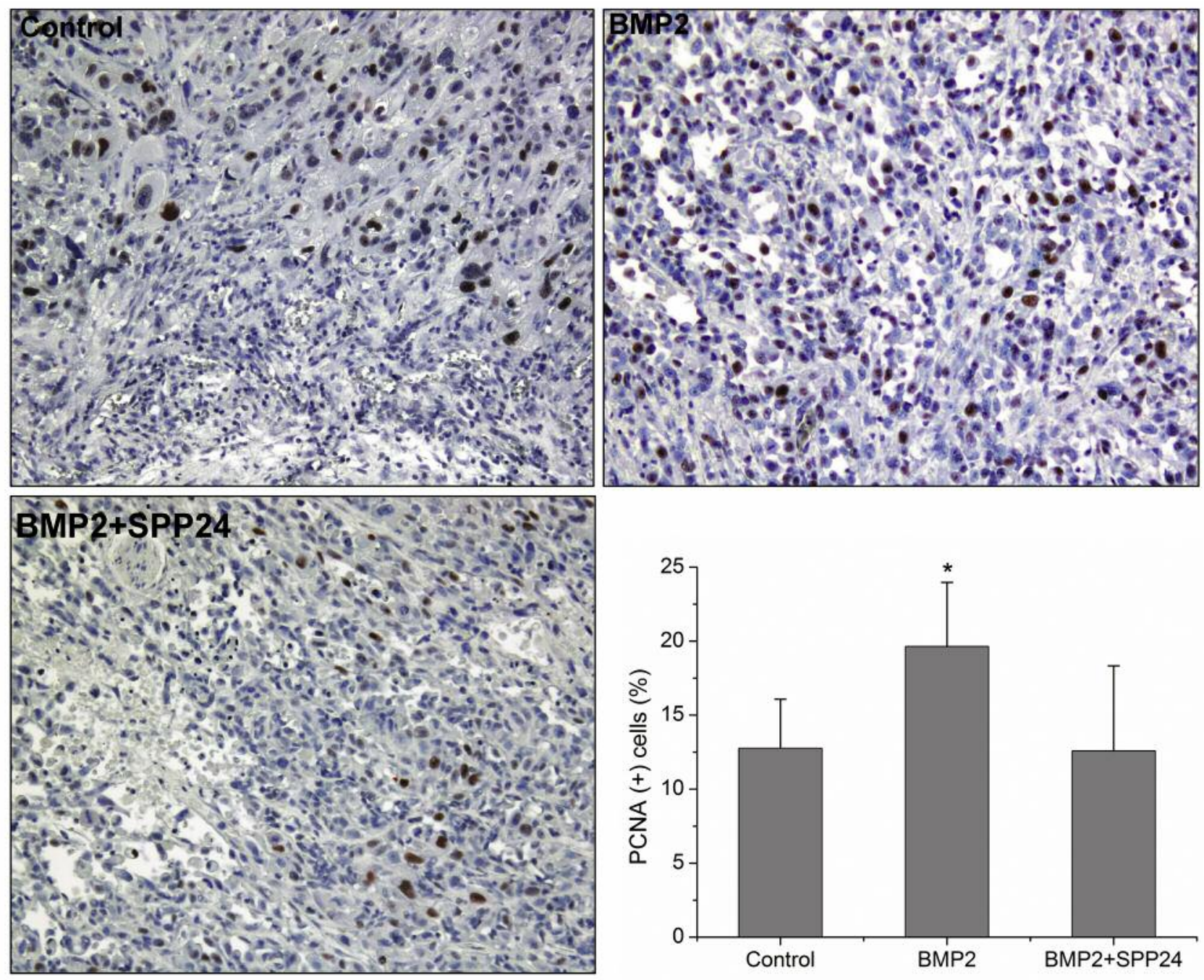

Figure 5. Immunohistochemical staining for proliferating cell nuclear antigen-1 (PCNA-1) in vivo specimens $(\times 100)$. More PCNA-1 positive cells were found in bone morphogenetic protein2 (BMP2) group compared with control and BMP+ secreted phosphoprotein $24 \mathrm{kD}$ (SPP24) group. ${ }^{*} p<0.01$ vs. control and BMP $2+S P P 24$ group.

\section{Conflicts of Interest}

The Authors declare that they have no conflict of interest.

\section{References}

1 Siegel RL, Miller KD and Jemal A: Cancer statistics, 2015. CA Cancer J Clin 65(1): 5-29, 2015.

2 Siegel R, Naishadham D and Jemal A: Cancer statistics, 2013. CA Cancer J Clin 63(1): 11-30, 2013.

3 Gundem G, Van Loo P, Kremeyer B, Alexandrov LB, Tubio JM, Papaemmanuil E, Brewer DS, Kallio HM, Hognas G, Annala M, Kivinummi K, Goody V, Latimer C, O'Meara S, Dawson KJ, Isaacs W, Emmert-Buck MR, Nykter M, Foster C, Kote-Jarai Z, Easton D, Whitaker HC, Neal DE, Cooper CS, Eeles RA,
Visakorpi T, Campbell PJ, McDermott U, Wedge DC and Bova GS: The evolutionary history of lethal metastatic prostate cancer. Nature 520(7547): 353-357, 2015.

4 Merglen A, Schmidlin F, Fioretta G, Verkooijen HM, Rapiti E, Zanetti R, Miralbell R and Bouchardy C: Short- and long-term mortality with localized prostate cancer. Arch Intern Med 167(18): 1944-1950, 2007.

5 Gundala SR, Yang C, Lakshminarayana N, Asif G, Gupta MV, Shamsi S and Aneja R: Polar biophenolics in sweet potato greens extract synergize to inhibit prostate cancer cell proliferation and in vivo tumor growth. Carcinogenesis 34(9): 2039-2049, 2013.

6 Li K, Dias SJ, Rimando AM, Dhar S, Mizuno CS, Penman AD, Lewin JR and Levenson AS: Pterostilbene acts through metastasisassociated protein 1 to inhibit tumor growth, progression and metastasis in prostate cancer. PLoS One 8(3): e57542, 2013. 
7 Rick FG, Schally AV, Szalontay L, Block NL, Szepeshazi K, Nadji M, Zarandi M, Hohla F, Buchholz S and Seitz S: Antagonists of growth hormone-releasing hormone inhibit growth of androgen-independent prostate cancer through inactivation of ERK and Akt kinases. Proc Natl Acad Sci USA 109(5): 1655-1660, 2012.

8 Tanaka H, Kono E, Tran CP, Miyazaki H, Yamashiro J, Shimomura T, Fazli L, Wada R, Huang J, Vessella RL, An J, Horvath S, Gleave M, Rettig MB, Wainberg ZA and Reiter RE: Monoclonal antibody targeting of $\mathrm{N}$-cadherin inhibits prostate cancer growth, metastasis and castration resistance. Nat Med 16(12): 1414-1420, 2010.

9 Hsu YH, Wu CY, Hsing CH, Lai WT, Wu LW and Chang MS: Anti-IL-20 Monoclonal Antibody Suppresses Prostate Cancer Growth and Bone Osteolysis in Murine Models. PLoS One 10(10): e139871, 2015.

10 Jin M, Zhang T, Liu C, Badeaux MA, Liu B, Liu R, Jeter C, Chen X, Vlassov AV and Tang DG: miRNA-128 suppresses prostate cancer by inhibiting BMI-1 to inhibit tumor-initiating cells. Cancer Res 74(15): 4183-4195, 2014.

11 Zhao X, Wang Y, Deng R, Zhang H, Dou J, Yuan H, Hou G, Du $\mathrm{Y}$, Chen $\mathrm{Q}$ and $\mathrm{Yu} \mathrm{J}$ : miR186 suppresses prostate cancer progression by targeting Twist1. Oncotarget doi: doi: 10.18632/oncotarget.8887, 2016.

12 Bleuming SA, He XC, Kodach LL, Hardwick JC, Koopman FA, Ten KF, van Deventer SJ, Hommes DW, Peppelenbosch MP, Offerhaus GJ, Li L and van den Brink GR: Bone morphogenetic protein signaling suppresses tumorigenesis at gastric epithelial transition zones in mice. Cancer Res 67(17): 8149-8155, 2007.

13 Thawani JP, Wang AC, Than KD, Lin CY, La Marca F and Park P: Bone morphogenetic proteins and cancer: review of the literature. Neurosurgery 66(2): 233-246, 246, 2010.

14 Langenfeld EM, Kong Y and Langenfeld J: Bone morphogenetic protein 2 stimulation of tumor growth involves the activation of Smad-1/5. Oncogene 25(5): 685-692, 2006.

15 Kokorina NA, Zakharkin SO, Krebsbach PH and Nussenbaum B: Treatment effects of rhBMP-2 on invasiveness of oral carcinoma cell lines. Laryngoscope 121(9): 1876-1880, 2011.

16 Kang MH, Oh SC, Lee HJ, Kang HN, Kim JL, Kim JS and Yoo YA: Metastatic function of BMP-2 in gastric cancer cells: the role of PI3K/AKT, MAPK, the NF-kappaB pathway, and MMP9 expression. Exp Cell Res 317(12): 1746-1762, 2011.

17 Dai J, Keller J, Zhang J, Lu Y, Yao Z and Keller ET: Bone morphogenetic protein-6 promotes osteoblastic prostate cancer bone metastases through a dual mechanism. Cancer Res 65(18): 8274-8285, 2005.

18 Ide H, Yoshida T, Matsumoto N, Aoki K, Osada Y, Sugimura T and Terada M: Growth regulation of human prostate cancer cells by bone morphogenetic protein-2. Cancer Res 57(22): 50225027, 1997.

19 Feeley BT, Krenek L, Liu N, Hsu WK, Gamradt SC, Schwarz EM, Huard J and Lieberman JR: Overexpression of noggin inhibits BMP-mediated growth of osteolytic prostate cancer lesions. Bone 38(2): 154-166, 2006.
20 Tian H, Bi X, Li CS, Zhao KW, Brochmann EJ, Montgomery SR, Aghdasi B, Chen D, Daubs MD, Wang JC and Murray SS: Secreted phosphoprotein $24 \mathrm{kD}$ (Spp24) and Spp14 affect TGFbeta induced bone formation differently. PLoS One 8(8): e72645, 2013.

21 Tian H, Li CS, Zhao KW, Wang JC, Duarte ME, David CL, Phan K, Atti E, Brochmann EJ and Murray SS: A carboxy terminal BMP/TGF-beta binding site in secreted phosphoprotein $24 \mathrm{kD}$ independently affects BMP-2 activity. J Cell Biochem 116(4): 667-676, 2015.

22 Li CS, Tian H, Zou M, Zhao KW, Li Y, Lao L, Brochmann EJ, Duarte ME, Daubs MD, Zhou YH, Murray SS and Wang JC: Secreted phosphoprotein $24 \mathrm{kD}$ (Spp24) inhibits growth of human pancreatic cancer cells caused by BMP-2. Biochem Biophys Res Commun 466(2): 167-172, 2015.

23 Lee KB, Murray SS, Duarte ME, Spitz JF, Johnson JS, Song KJ, Brochmann EJ, Taghavi CE, Keorochana G, Liao JC and Wang JC. Effects of the bone morphogenetic protein binding protein spp24 (secreted phosphoprotein $24 \mathrm{kD}$ ) on the growth of human lung cancer cells. J Orthop Res 29(11): 1712-1718, 2011.

24 Kwon H, Kim HJ, Rice WL, Subramanian B, Park SH, Georgakoudi I and Kaplan DL: Development of an in vitro model to study the impact of BMP-2 on metastasis to bone. J Tissue Eng Regen Med 4(8): 590-599, 2010.

25 Murray EJ, Murray SS, Simon R and Behnam K: Recombinant expression, isolation, and proteolysis of extracellular matrixsecreted phosphoprotein-24 kDa. Connect Tissue Res 48(6): 292-299, 2007.

26 Masuda H, Fukabori Y, Nakano K, Takezawa Y, CSuzuki T and Yamanaka H: Increased expression of bone morphogenetic protein-7 in bone metastatic prostate cancer. Prostate 54(4): 268274, 2003.

27 Feeley BT, Gamradt SC, Hsu WK, Liu N, Krenek L, Robbins P, Huard J and Lieberman JR: Influence of BMPs on the formation of osteoblastic lesions in metastatic prostate cancer. J Bone Miner Res 20(12): 2189-2199, 2005.

28 Brochmann EJ, Simon RJ, Jawien J, Behnam K, Sintuu C, Wang JC and Murray SS: Carboxy terminus of secreted phosphoprotein-24 $\mathrm{kDa}$ (spp24) is essential for full inhibition of BMP-2 activity. J Orthop Res 28(9): 1200-1207, 2010.

29 Sintuu C, Murray SS, Behnam K, Simon R, Jawien J, Silva JD, Duarte ME and Brochmann EJ: Full-length bovine spp24 [spp24 (24-203)] inhibits BMP-2 induced bone formation. J Orthop Res 26(6): 753-758, 2008.

30 Lai TH, Fong YC, Fu WM, Yang RS and Tang CH: Osteoblastsderived BMP-2 enhances the motility of prostate cancer cells via activation of integrins. Prostate 68(12): 1341-1353, 2008.

Received June 7, 2016

Revised July 4, 2016

Accepted July 5, 2016 